\title{
Erratum to: Optimal double screw configuration for subtalar arthrodesis: a finite element analysis
}

Jun Young Lee $\cdot$ Yeon Soo Lee

Published online: 25 February 2011

(C) Springer-Verlag 2011

Erratum to: Knee Surg Sports Traumatol Arthrosc

DOI 10.1007/s00167-010-1383-y

In the original published article, unfortunately, a wrong version of Fig. 1 is presented (part b is also published as Fig. 2). The correct Fig. 1 and caption is given here.

Fig. 1 Double screw configurations for subtalar arthrodesis

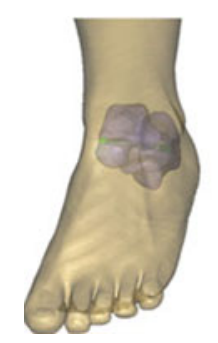

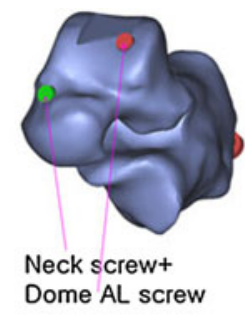
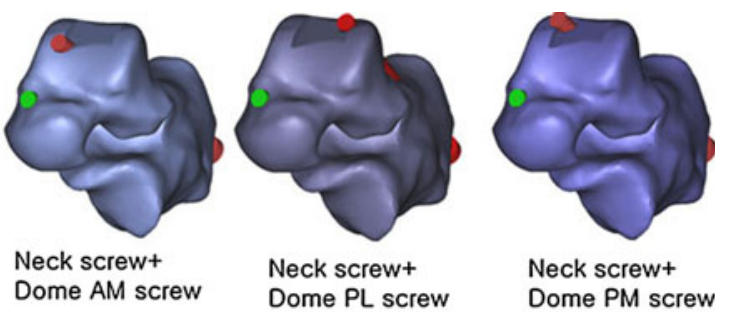

The online version of the original article can be found under doi:10.1007/s00167-010-1383-y.

\section{J. Y. Lee}

Department of Orthopaedic Surgery, College of Medicine,

Chosun University, Gwangju, Republic of Korea

\section{Y. S. Lee $(\bowtie)$}

Department of Biomedical Engineering,

College of Medical Science, Catholic University of Daegu,

330 Geumrak, Hayang-eup, Gyeongsan-si,

Gyeongbuk 712-702, Republic of Korea

e-mail: biomechanics.yslee@gmail.com

URL: http://biomechanics.cu.ac.kr 